\title{
Investigation of the protective effect of thymoquinone of U87 cells induced by beta-amyloid
}

\author{
Ozbolat $\mathrm{G}^{1}$, Alizade $\mathrm{A}^{2}$ \\ Sinop University, Faculty of Health Science, Sinop, Turkey. guluzarozbolat@gmail.com
}

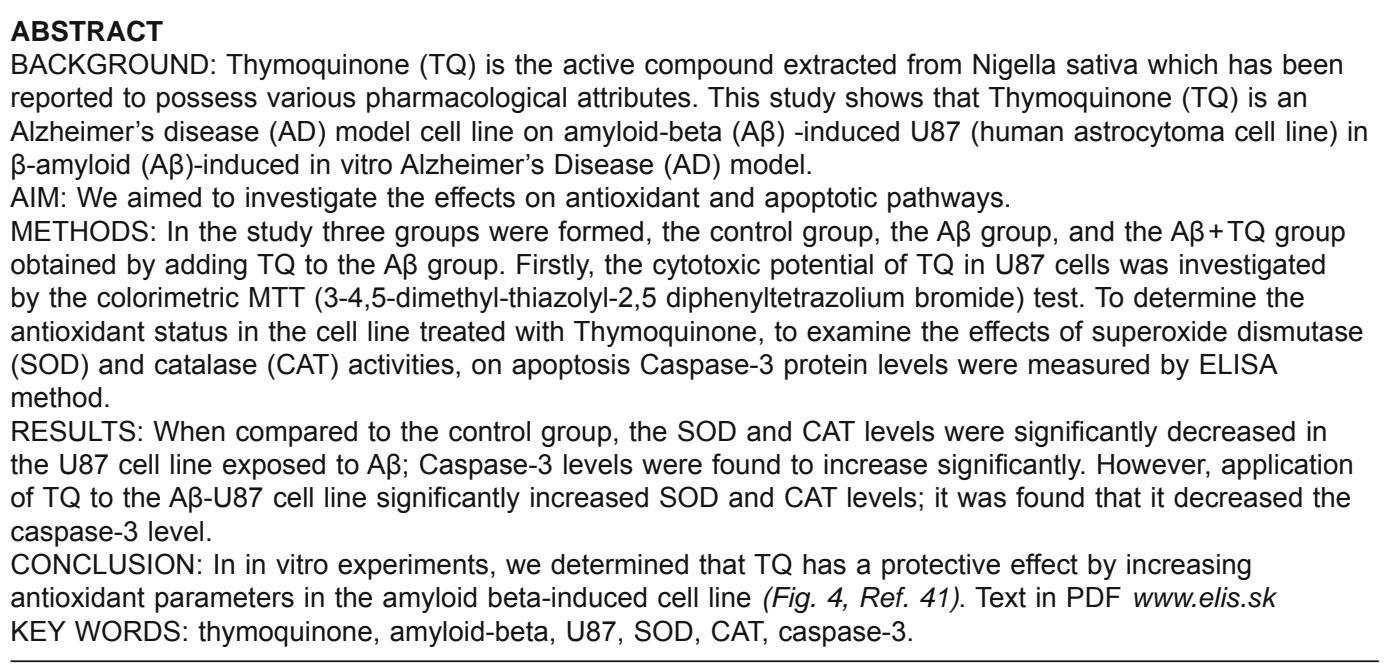

\section{Introduction}

Alzheimer's Disease (AD) is believed to be one of the most prevalent neurodegenerative diseases known and is characterized by a variety of symptoms, such as memory loss, decreased cognitive function, abnormal behavior, and psychiatric problems. Even though the exact cause of AD is not known, advanced age, hereditary factors, death of brain cells, impairment of neural conduction, and various toxic substances are thought to trigger the disease. Neuritic plaques and neurofibrillary tangles show pathological features of $\mathrm{AD}$. AD is characterized by abnormal beta-amyloid $(A \beta)$ accumulation in brain tissues, death of cholinergic neurons, tangles caused by hyperphosphorylation of microtubule-associated tau protein, dyshomeostasis of metals, such as copper, iron, zinc and aluminum, metal-induced oxidative stress, and various other factors. It is multifactorial with an unknown etiology, characterized by various pathological symptoms $(1,2,3,4)$.

There are studies reporting that factors like genetic mutations, synapse loss, aging, and the accumulation of biometals, such as

${ }^{1}$ Sinop University, Faculty of Health Science, Sinop, Turkey, and ${ }^{2}$ Mustafa Kemal University, Faculty of Veterinary, Department of Pharmacology, Hatay, Turkey

Address for correspondence: G. Ozbolat, Sinop University, Faculty of Health Science, 57000 Sinop, Turkey. iron, copper, and zinc, might be responsible for the pathophysiology of AD. However, the most widely accepted point of view is that oxidative stress and amyloid plaques in the extracellular area of the brain and Neurofibrils in neurons are most important. It is the classical theory based on the formation of tangles $(5,6,7)$.

$\mathrm{A} \beta$ causes neurotoxic effects by triggering an increase in reactive oxygen/nitrogen products, resulting in loss of mitochondrial function, decreased ATP production, impaired intracellular calcium homeostasis, neuronal loss, and synapse, dendrite, and axon degeneration $(8,9)$.

The increased production of $A \beta$ in the brain of Alzheimer's patients compared to a normal individuals leads to the formation of amyloid plaques in the brain tissue, which could be demonstrated histologically $(10,11,12)$.

Currently, the most prominent targets for therapeutic intervention include the inhibition of amyloid precursor protein (APP) and $A \beta$ production by blocking $A \beta$ aggregation and the resulting inflammatory response and inhibiting $A \beta$-induced neurotoxicity. Age-related memory impairments have been depicted to be associated with decreased antioxidant mechanisms in the brain and plasma. The interaction of $A \beta 42$ plaques with free radicals and the oxidative stress as a result of it may play a pivotal role in $\mathrm{AD}$ pathogenesis $(13,14)$.

The use of herbal medicines as an alternative approach is on an increasing trend due to the insufficiency of traditional medi- 
cines and the side effects of synthetic medicines. Thymoquinone (TQ) is the active compound extracted from Nigella sativa. Several pharmacological actions of TQ have been investigated, including anti-tumor, anti-histaminic, anti-inflammatory, and antioxidant effects and neuroprotective properties. Therefore, it could be a good candidate for the recovery of Alzheimer's Disease (AD) pathology rather than current symptomatic relief (15-19).

It is thought that TQ could be utilized effectively for the treatment of Alzheimer's Disease and we anticipate that it could be evaluated among alternative treatment strategies in the field of medicine.

\section{Materials and methods}

\section{Cell viability}

Cell count was carried out for the U87 cell line and the viability of the cells was measured with trypan blue excretion test. By placing $10 \mu \mathrm{L}$ of the cells $+10 \mu \mathrm{L}$ of trypan blue on a slide, the viability was determined counting the cells that did not receive dye under the light microscope. The percentage of non-staining cells was calculated by counting 100 cells in the area.

\section{Cell culture}

Later, the cells were prepared with a medium at 104 cells per $\mathrm{mL}$ in the cell line. For each complex, $3 \mathrm{~mL}$ of cell suspension was added to 7 wells in a separate 12 -well culture plate. All the plates were left to incubate for 24 hours in a $\mathrm{CO} 2$ incubator at $37^{\circ} \mathrm{C}$ in an environment containing $5 \% \mathrm{CO} 2$. Following the incubation, the cell concentrations we added to the 12-well plates, which comprised of U87 cell series, were added to the first well cell and medium, and the second well was determined by determining the solvent containing DMSO as a control. Active ingredients were added to the well at five different concentrations $(200 \mu \mathrm{M}, 100$ $\mu \mathrm{M}, 50 \mu \mathrm{M}, 25 \mu \mathrm{M}, 12.5 \mu \mathrm{M})$. The plates were again incubated in a $\mathrm{CO} 2$ incubator for 48 hours.

\section{Working groups}

Control group: $50 \mu \mathrm{l}$ of saline was added to the medium of differentiated U87 cells and incubated for 48 hours. At the end of this period, Dimethyl Sulfoxide (DMSO) was added to the medium of the cells in a final concentration of $0.1 \%$ and the cells were incubated for another 24 hours in the incubator.

A $\beta$ group: $A \beta 1-42$ was added to the medium of the differentiated U87 MG cells at a concentration of $5 \mu \mathrm{M}$ and incubated for 48 hours. At the end of this period, DMSO was added to the medium of the cells in a final concentration of $0.1 \%$ and the cells were incubated for another 24 hours in the incubator.

$\mathrm{A} \beta+$ TQ group: The differentiated U87 cells were added to the culture medium at a final concentration of $5 \mu \mathrm{M}, 48$ hours after A $\beta 1-42$ application. $300 \mu \mathrm{mol} / \mathrm{L}$ Thymoquinone was added and the mixture was incubated for another 24 hours.

Cytotoxicity: At the end of the 48 hours, U87 cell line cells were transferred to 96 well plates with $100 \mu \mathrm{L}$ of cell suspension per well and $10 \mu \mathrm{L}$ of MTT solution was added to each well and incubated for 4 hours. The MTT solution was prepared by dis- solving it in PBS as $5 \mathrm{mg} / \mathrm{mL}$ and transferring it to a bottle with sterile filtration. Afterwards, $100 \mu \mathrm{L}$ of DMSO was added to each well and the well was kept in a $\mathrm{CO}_{2}$ incubator at $37^{\circ} \mathrm{C}$ for $10 \mathrm{mi}-$ nutes to dissolve the formazon crystals formed by MTT. Each well was read at $570 \mathrm{~nm}$ wavelength with a microplate reader and the cytotoxicity level was determined according to the absorbance value read. Their cytotoxicity levels were calculated employing the following formula.

1- (the absorbance of the test pad - the absorbance of the control pad/the absorbance of the test pad) $x 100$ the concentration with $50 \%$ cytotoxic effect relative to the control was accepted as the cytotoxic dose.

ELISA (Enzyme Linked Immunosorbent Assay) Test: To evaluate the antioxidant status in the cell line treated with TQ, SOD, CAT activities, and caspase- 3 protein levels were measured based on ELISA method to examine its effect on the apoptosis process. Experimental protocols of ELISA kits vary for each kit.

\section{Results}

\section{MTT test}

The effect of thymoquinone-administered human brain cell line U87 (glioblastoma astrocytoma) on cell viability and proliferation was also investigated. Following the application of $A \beta 1-42$, the number of viable cells decreased in all the groups except for the control group $(p<0.05)$. After the application of Timokino on U87 cells, there was a significant statistical increase in the number of cells in the A $\beta+$ TQ group $(p<0.05)$ (Fig. 1). According to these results, it was determined that TQ increased cell survival in the in vitro $\mathrm{AH}$ model.

\section{SOD activity}

The application of amyloid-B to the cells significantly decreased the SOD (U/mg protein) enzyme level in all the groups except for the control group $(\mathrm{p}<0.05)$. The SOD enzyme level increased significantly in the A $\beta+$ TQ group after Timoquinone was applied on the U87 cell $(\mathrm{p}<0.05)$ (Fig. 2). It has been determined that TQ triggers the antioxidant enzyme mechanism.

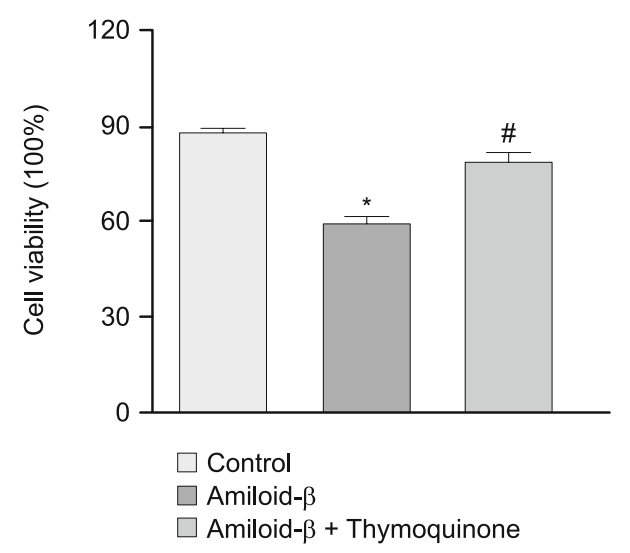

Fig. 1. Cell viability of the groups with TQ added versus Aß1-42 application. 


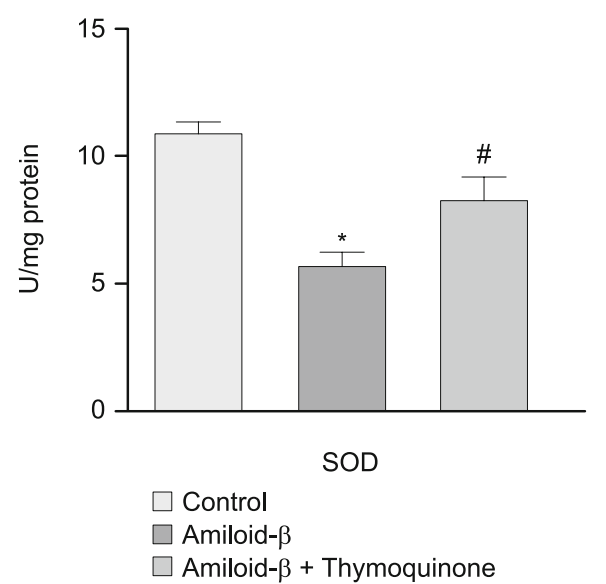

Fig. 2. SOD enzyme (U/mg) level values in the in vitro $\mathrm{AH}$ model cell lines.

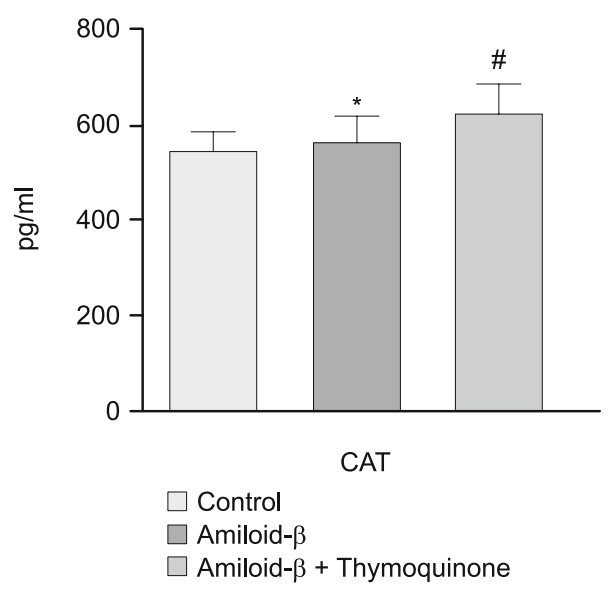

Fig. 3. CAT enzyme (pg/ml) level values in in vitro $\mathrm{AH}$ model cell lines.

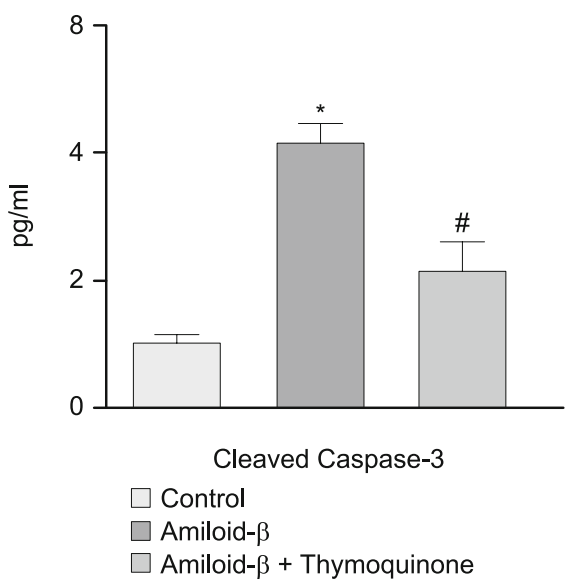

Fig. 4. Caspase-3 enzyme (pg/ml) level values in in vitro $\mathrm{AH}$ model cell lines.

\section{CAT activity}

Our findings indicated that CAT enzyme level (pg/ml) significantly decreased after $A \beta 1-42$ administration in all the groups except for the control group $(p<0.05)$. We observed a significant statistical increase in CAT enzyme level in the A $\beta+$ TQ group after Timoquinone was applied on the U87 cell ( $\mathrm{p}<0.05)$ (Fig. 3). Moreover, the results implied that TQ triggers the antioxidant enzyme mechanism.

\section{Caspase-3 activity}

The application of amyloid- $\beta$ to the cells significantly increased the Caspase- 3 enzyme activity ( $\mathrm{pg} / \mathrm{ml}$ protein) in all the groups except for the control group $(p<0.05)$. Caspase- 3 enzyme activity was found to be statistically and significantly lower in the A $\beta+$ TQ group after Timokinoon was applied on the U87 cell ( $<<0.05)$ (Fig. 4).

\section{Discussion}

Reactive oxygen species (ROS) containing hydroxyl radicals $\left(\mathrm{OH}\right.$.), Superoxide anion, and hydrogen peroxide $\left(\mathrm{H}_{2} \mathrm{O}_{2}\right)$ are considered to be of great importance in the formation of cancer and various diseases by acting on cell metabolism. Reactive oxygen species (ROS) are generated during aerobic cellular reactions and are effectively cleared by the cell's detoxification defense system, such as superoxide dismutase (SOD), catalase (CAT), and glutathione peroxidase (GPx) in order to maintain redox homeostasis. However, once ROS production exceeds the cell detoxification capacity, the overproduced ROS can directly alter lipid, protein, or DNA and signal transduction pathways resulting in an irreversible oxidative modification $(20,21,22)$.

The oxidative stress caused by the disruption of the balance between the production of reactive oxygen species (ROS)/reactive nitrogen species (RNS) and the antioxidant defense mechanism is another major factor implicated in the pathogenesis of Alzheimer's. Excessive accumulation of free radicals, the increase in protein oxidation, and lipid 71 peroxidation level due to the changes in the redox state in the brains of patients with Alzheimer's Disease appear as a common pathological features of AD. However, studies have shown that oxidative stress leads to neuronal cell dysfunction, $A \beta$ accumulation, cell death, and cognitive dysfunction. This indicates that oxidative stress occurs in the early stages of AD. It is also known that $\mathrm{A} \beta$ causes mitochondrial damage by increasing ROS production in the brain. Therefore, antioxidant therapy is considered as a new therapeutic approach to the prevention and symptomatic treatment of AD23-27. In our study, we aimed to examine the effects of TQ on the human brain cell line U87 (glioblastoma astrocytoma), which is an Alzheimer's model. The MTT method was employed in order to examine the effects on cell proliferation and vitality and investigate the effects on the antioxidant defense system, superoxide dismutase (SOD), and catalase (CAT) activities. Caspase-3 protein levels were measured with ELISA method to examine the effects on the apoptosis process. In some studies, a difference has been reported between $\mathrm{AD}$ and controls in terms of SOD, yet it was not statistically significant. On the contrary, other studies have shown that the SOD level increased significantly. 
According to the obtained data herein, amyloid-B administration significantly reduced SOD activity on human brain cell line U87 (glioblastoma astrocytoma) cells compared to the controls. We found that TQ application significantly augmented this decrease and implied an antioxidant effect. In the studies in the literature, different results were obtained with the change of SOD expression and activity in patients with Alzheimer's Disease. On top of the findings showing a significant decrease in SOD activity in the cerebral cortex and hippocampus, there are researches indicating no differences in SOD activity compared to controls. It has been determined that TQ triggers the antioxidant enzyme mechanism (28-32).

The results herein illustrated that CAT enzyme level (pg/ml) significantly decreased after A $\beta 1-42$ administration in all the groups except for the control group $(p<0.05)$. Moreover, we observed a significant statistical increase in CAT enzyme level in the A $\beta+$ TQ group after Timoquinone was applied on the U87 cell $p<0.05$ ) (Fig. 2). It has been determined that TQ triggers the antioxidant enzyme mechanism.

In addition, the increase in the level of antioxidant enzyme CAT in the in vitro $\mathrm{AD}$ group compared to the control and its decrease with TQ application, along with the increase in the free radicals in $\mathrm{AD}$, is indicative of an increase in enzymatic antioxidant activation in order to eliminate the toxic effects of these radicals. The oxidative stress induced by $\mathrm{A} \beta$ and the antioxidant defense mechanism associated with them are accepted as basic mechanisms in the etiology and pathogenesis of Alzheimer's. As a result of the disruption of the balance between antioxidant and oxidant systems, free radicals emerge. It protects the cell against oxidative stress by eliminating these radicals, which are SOD, GSH-Px, CAT; they are endogenous enzymes involved in the antioxidant defense mechanism(34-36).

Caspase-3, a protease, is thought to be an important driver caspase in apoptosis. The creation of active caspase- 3 performs an irreversible step of the apoptotic pathway. Numerous studies have revealed high caspase- 3 levels in AD. Caspase- 3 was analyzed in the study groups, representing apoptotic pathways. We found that caspase-3 level increased significantly in U87 cell lines exposed to $A \beta$ compared to that in the control group(36-41).

\section{Conclusion}

U87 supports the antioxidant defense system in the Alzheimer's cell line model, significantly increasing the levels of CAT and SOD while decreasing the level of caspase-3, the apoptotic pathway enzyme. TQ represented antioxidant activity and decreased neurodegeneration due to apoptosis. Therefore, the treatment with TQ could be suggested as a novel therapeutic approach to the prevention and symptomatic treatment of Alzheimer's.

\section{References}

1. Jalili-Baleh L, Babaei E, Abdpour S, Bukhari SNA, Foroumadi A, Ramazani A, Sharifzadeh M, Abdollahi M, Khoobi M. A review on flavonoid-based scaffolds as multi-target-directed ligands (MTDLs) for Alzheimer's disease. Eur J Med Chem 2018; 152: 570-589.
2. Alzheimer's Association. 2019 Alzheimer's disease facts and figures. Alzheimer's \& Dementia 2019; 15: 321-387.

3. Hippius H, Neundörfer G. The discovery of Alzheimer's disease. Dia$\log$ Clin Neurosci 2003; 5: 101.

4. Crimins JL, Pooler A, Polydoro M, Luebke JI, Spires-Jones TL. The intersection of amyloid beta and tau in glutamatergic synaptic dysfunction and collapse in Alzheimer's disease. Ageing Res Rev 2013; 12: 757-763.

5. Dumont M, Beal MF. Neuroprotective strategies involving ROS in Alzheimer disease. Free Rad Biol Med 2011; 51: 1014-10026.

6. Prakash A, Dhaliwal GK, Kumar P, Majeed ABA. Brain biometals and Alzheimer's disease - boon or bane? Internat J Neurosci 2016; 1-10.

7. Dgachi Y, Sokolov O, Luzet V, Godyń J, Panek D, Bonet A, Martin H, Iriepa I, Moraleda I, García-Iriepa C et al., Tetrahydropyranodiquinolin-8-amines as new, non hepatotoxic, antioxidant, and acetylcholinesterase inhibitors for Alzheimer's disease therapy. Eur J Med Chem 2017; 126: 576-589.

8. Hettiarachchi N, Dallas M, Al-Owais M, et al. Heme oxygenase-1 protects against Alzheimer's amyloid- $\beta 1-42$-induced toxicity via carbon monoxide production. Cell Death Dis 2014; 5 (12): e1569.80.

9. Huang W, Zhang X, Chen W. Role of oxidative stress in Alzheimer's disease (Review). Biomed Report 2016; 4: 519-522.

10. Chen JH, Ke KF, Lu JH, Qiu YH, Peng YP. Protection of TGF- $\beta 1$ against neuroinflammation and neurodegeneration in A $\beta 1$-42-induced Alzheimer's disease model rats. PLoS One 2015; 10 (2): e0116549.

11. Reitz C, Mayeux R. Alzheimer disease: epidemiology, diagnostic criteria, risk factors and biomarkers. Biochem Pharmacol 2014; 88 (4): 640-651.

12. Swomley AM, Förster S, Keeney JT, Triplett J, Zhang Z, Sultana R, Butterfield DA. Abeta, oxidative stress in Alzheimer disease: evidence based on proteomics studies. Biochim Biophys Acta 2014; 1842 (8): 1248-1257.

13. Dinamarca MC, Cerpa W, Garrido J, Hancke JL, Inestrosa NC. Hyperforinprevents betaamyloidneurotoxicity and spatial memory impairments by disaggregation of Alzheimer's amyloidbeta-deposits. Mol Psychiatry 2006; 11 (11): 1032-1048.

14. Talib WH, Zarga MH, Mahasneh AN. Antiproliferative, Antimicrobial and Apoptosis Inducing Effects of Compounds Isolated from Inulaviscosa. Molecules 2012; 17: 3291-3303.

15. Mostofa AGM. Hossain MDK. Basak D. Sayeed MSB. Thymoquinone as a Potential Adjuvant Therapy for Cancer Treatment: Evidence from Preclinical Studies.

16. Aggarwal BB, Harikumar KB. Potential therapeutic effects of curcumin, the anti inflammatory agent, against neurodegenerative, cardiovascular, pulmonary, metabolic, autoimmune and neoplastic diseases. Int J Biochem Cell Biol 2009; 41: 40-59.

17. Park MY, Jeong YJ, Kang GC, et al. Nitric oxide-induced apoptosis of human dental pulp cells is mediated by the mitochondria-dependent pathway. Korean J Physiol Pharmacol 18: 25-32.

18. Susin SA, Lorenzo HK, Zamzami N, Marzo I, Snow BE, Brothers GM, Mangion, J, Jacotot $\mathbf{E}$ et al. Molecular characterization of mitochondrial apoptosis-inducing factor. Nature 1999; 397: 441-446.

19. Hassan SA, Ahmed WA, Galeb FM, El-Taweeld MA, Abu-Bedair FA. In vitro challenge using thymoquinone on hepatocellular carcinoma (HepG2) cell line. Iran J Pharm Res 2008; 7 (4): 283-290. 


\section{$748-752$}

20. Lin CW, Yang LY, Shen SC, Chen YC. IGF-I plus E2 induces proliferation via activation of ROS-dependent ERKs and JNKs in human breast carcinoma cells. J Cell Physiol 2007; 212 (3): 666-764.

21. Zhu X, Lee HG, Moreira PI, Smith MA, Perry G. Presenilin mutation: A deadly first hit in Alzheimer disease - A commentary on "aging sensitizes towards ROS formation and lipid peroxidation in PS1M146L transgenic mice". Free Rad Biol Med 2006; 40 (5): 737-739.

22. Oh PS, Lim KT. Blocking of intracellular ROS production by phytoglycoprotein $(30 \mathrm{kDa})$ causes anti-proliferation.

23. Aka TD, Rashid MMO, Paul SC, Halim MA. A review on molecular neuropathology of Alzheimer's disease in association with aging. J Res Pharm 2019; 23 (1): 1-15.

24. Farzaei MH, Bahramsoltani R, Abbasabadi Z, Braidy N, Nabavi SM. Role of green tea catechins in prevention of age-related cognitive decline: Pharmacological targets and clinical perspective. J Cell Physiol 2019; 234 (3): 2447-2459.

25. Prakash A, Dhaliwal GK, Kumar P, Majeed ABA. Brain biometals and Alzheimer's disease - boon or bane? Internat J Neurosci 2016; 1-10.

26. Ni J, Wu Z, Meng J, Zhu A, Zhong X, Wu S, Nakanishi H. The Neuroprotective Effects of Brazilian Green Propolis on Neurodegenerative Damage in Human Neuronal SH-SY5Y Cells. Oxid Med Cell Longev 2017; 2017: 7984327.

27. Cheignon C, Tomas M, Bonnefont-Rousselot D, Faller P, Hureau C, Collin F. Oxidative stress and the amyloid beta peptide in Alzheimer's disease. Redox Biol 2018; 14: 450-464.

28. Tabet N, Mantle D, Walker Z, Orrell M. Vitamins, trace elements, and antioxidant status in dementia disorders. International Psychogeriatrics 2001; 13 (3): 265-275 2001.

29. Cristalli D O, Arnal N, Marra F A, De Alaniz M J T, Marra C A. Peripheralmarkers in neurodegenerative patients and their first-degree relatives. J Neurol Sci 2012; 314 (1-2): 48-56.

30. Kumar R, Lal N, Nemaysh V, Luthra PM. Demethoxycurcumin mediated targeting of MnSOD leading to activation of apoptotic pathway and inhibition of Akt/NF- $\mathrm{\kappa B}$ survival signalling in human glioma U87 MG cells. Toxicol ApplPharmacol 2018; 345: 75-93.

31. Lovell MA, Ehmann WD, Butler SM, Markesbery WR. Elevated Thiobarbituric Acid-Reactive Substances and Antioxidant Enzyme Activity in the Brain in Alzheimers Disease. Neurology 1995; 45 (8): 1594-1601.
32. Gsell W, Conrad R, Hickethier M, Sofic E, Frolich L, Wichart I, Jellinger K, Moll G, Rnsmayr G, Beckmann H et al. Decreased Catalase Activity but Unchanged Sueroxide-Dismutase Activity in Brains of Patients with Dementia of Alzheimer-Tye. J Neurochem 1995; 64 (3): 1216-1223.

33. Medhat D, El-Mezayen HA, El-Naggar ME, Farrag AR, Abdelgawad ME, Hussein J, Kamal MH. Evaluation of urinary 8-hydroxy2-deoxyguanosine level in experimental Alzheimer's disease: Impact of carvacrol nanoparticles. Mol Biol Rep 2019; 46 (4): 4517- 4527.

34. Mohandas E, Rajmohan V, Raghunath B. Neurobiology of Alzheimer's disease. Indian J Psychiatry 2009; 51 (1): 55-54.

35. Wang P, Luo Q, Qiao H, Ding H, Cao Y, Yu J, Liu R, Zhang Q, Zhu H, Qu L. The Neuroprotective Effects of Carvacrol on Ethanol-Induced Hippocampal Neurons Impairment via the Antioxidative and Antiapoptotic Pathways. Oxid Med Cell Longev 2017; 2017: 4079425.

36. Fisher A, Hanin I. Potential animal models for senile dementia of Alzheimer's type, with emphasis on AF64A-induced cholinotoxicity. Ann Rev Pharmacol Toxicol 1986; 26 (1): 161-181.

37. Wolf BB, Schuler M, Echeverri F. Green DR. Caspase-3 Is the Primary Activator of Apoptotic DNA Fragmentation via DNA Fragmentation Factor-45/Inhibitor of Caspase-Activated DNase Inactivation. J Biol Chem 1999; 274.

38. Su JH, Zhao M, Anderson AJ, Srinivasan A. Cotman, CW. Activated Casapse-3 Expression in Alzheimer's and Aged Control Brain: Correlation with Alzheimer Pathology. Brain Res 2001; 898: 350-357.

39. Gastard MC, Troncoso JC. Koliatsos. Caspase Activation in the Limbic Cortex of Subjects with Early Alzheimer's Disease. Ann Neurol 2003; 54: 393-398.

40. Stadelmann C, Deckwerth TL, Srinivasan A, Bancher C, Brück W, Jellinger K. Lassmann, H. Activation of Casapse-3 in Single Neurons and Autophagic Granules of Granulovacuolar Degeneration in Alzheimer's Disease. Evidence for Apoptotic Cell Death. Amer J Pathol1999; 155: 1459-1465.

41. Kovacs DM, Mancini R, Henderson J, Na SJ, Schmidt SD, Kim TW. Tanzi RE. Staurosporine-Induced Activation of Caspase-3 in Potentiated by Presenilin 1 Fanmilial Alzheimer's Disease Mutations in Human Neuroglioma Cells. J Neurochem 1999; 73: 2278-2285.

Received March 9, 2021. Accepted April 24, 2021. 